\title{
Revisão sobre a influência da corrosão em estruturas de concreto armado e seus principais métodos de proteção e reabilitação
}

\author{
B. B. Mariani ${ }^{1 *}$, M. S. C. Silva ${ }^{2}$ \\ *Autor de Contato: brunabmariani@gmail.com \\ ${ }^{1}$ Área 1 - Faculdade de Ciência e Tecnologia, ÁREA1/CBES, Salvador-BA, Brasil. \\ ${ }^{2}$ Área 1 - Faculdade de Ciência e Tecnología, ÁREA 1/CBES, Salvador-BA, Brasil.
}

\section{Resumo}

Embora o concreto armado seja considerado um composto de alta durabilidade, alguns mecanismos de degradação podem levar à sua deterioração. A degradação associada à corrosão é uma das principais manifestações patológicas relacionadas à deterioração das estruturas de concreto armado. Por isso, estudos que buscam medidas de proteção do aço, contra os efeitos da corrosão são essenciais. O presente estudo faz uma pesquisa bibliográfica a respeito dos processos de degradação de armaduras de estruturas de concreto armado devido à contaminação por cloretos e por carbonatação, além de apresentar seus principais métodos de proteção e reabilitação. Os resultados da pesquisa demostraram que os métodos de proteção, quando utilizados corretamente, possuem grande potencial para aumento da durabilidade das estruturas de concreto armado.

Palavras-chave: Degradação de Estruturas; Concreto Armado; Corrosão.

\section{Resumen}


Aunque el hormigón armado se considera un material compuesto de gran durabilidad, algunos mecanismos de degradación pueden provocar su deterioro. La degradación asociada a la corrosión es una de las principales manifestaciones patológicas relacionadas con el deterioro de las estructuras de hormigón armado. Por tanto, son fundamentales los estudios que busquen medidas para proteger el acero de los efectos de la corrosión. El presente estudio realiza una investigación bibliográfica sobre los procesos de degradación de armaduras de estructuras de hormigón armado por contaminación por cloruros y carbonatación, además de presentar sus principales métodos de protección y rehabilitación. Los resultados de la investigación mostraron que los métodos de protección, cuando se utilizan correctamente, tienen un gran potencial para aumentar la durabilidad de las estructuras de hormigón armado.

Keywords: Degradación de Estructuras; Concreto armado; Corrosión.

\section{Resumo}

Although reinforced concrete is considered a highly durable composite, some degradation mechanisms can lead to its deterioration. Degradation associated with corrosion is one of the main pathological manifestations related to the deterioration of reinforced concrete structures. Therefore, studies that seek measures to protect steel against the effects of corrosion are essential. The present study makes a bibliographical research about the reinforcement degradation processes of reinforced concrete structures due to chloride and carbonation contamination, besides presenting its main protection and rehabilitation methods. The research results showed that protection methods, when used correctly, have great potential to increase the durability of reinforced concrete structures.

Keywords: Degradation of Structures; Reinforced Concrete; Corrosion.

\section{INTRODUÇÃO}


A corrosão é uma das manifestações patológicas mais recorrentes em estruturas de concreto armado. Trata-se do processo em que o metal presente no aço das armaduras, interage com o meio ambiente, ocorrendo uma diferença na concentração de íons dissolvidos no interior do concreto (RIBEIRO et al. 2018), podendo estar associada à fatores físicos (causados por variação de temperatura), mecânicos (vibrações e erosão), biológicos (micro-organismos) e químicos, que estão associados à presença de agentes agressores e contaminantes.

A deterioração de estruturas devido à corrosão da armadura é um dos principais problemas associados à durabilidade do concreto $\mathrm{e}$, tanto a gravidade do problema, como a frequência de ocorrência de corrosão da armadura, evidenciam a necessidade de buscar soluções que contribuam para minimizar a incidência e evolução do processo corrosivo nas estruturas de concreto (VIEIRA, 2003).

Desta forma, considerando a necessidade de aprofundamento do tema e os grandes prejuízos às estruturas, gerados pela corrosão, o presente artigo buscou fazer uma pesquisa bibliográfica, sobre os mecanismos de deterioração das estruturas, investigando a deterioração precoce do concreto armado influenciada pela corrosão, uma das principais causas da degradação em estruturas de concreto, apresentando métodos de prevenção e recuperação.

\section{CORROSÃO EM ESTRUTURAS DE CONCRETO ARMADO}

O concreto é um material compósito, não inerte, altamente utilizado na indústria da construção civil devido à disponibilidade de materiais para sua fabricação e uma diversificada aplicação, desde simples estruturas habitacionais até grandes e complexas obras. É constituído basicamente de cimento, água e agregados (graúdo e miúdo) aditivos químicos e armaduras.

$\mathrm{O}$ aço presente no concreto encontra-se envolto em uma proteção física, onde a espessura do cobrimento representa uma barreira física, que dificulta a entrada de agentes agressivos. Quando o concreto que envolve a armadura não é executado de forma correta, a espessura de cobrimento da armadura, pode não atuar como uma barreira, permitindo assim, a penetração de agentes agressivos, como o dióxido de carbono $\left(\mathrm{CO}_{2}\right)$ e os íons cloro $\left(\mathrm{Cl}^{-}\right)$, que são os principais responsáveis pela corrosão nas estruturas de concreto armado (OLIVEIRA, 2017).

\subsection{Princípios da Corrosão}

A corrosão é a deterioração de um material, metálico ou não metálico, como polímeros, concretos (compósitos) e cerâmicos, pela ação química ou eletroquímica do meio, podendo estar ligada ou não a esforços mecânicos. No caso das estruturas em concreto, a corrosão pode se apresentar em diferentes formas, comprometendo um ou vários trechos ao longo da estrutura, podendo ser classificada das seguintes formas: uniforme, puntiforme ou por pite, intergranular, transgranular e fragilidade pelo hidrogênio.

A corrosão uniforme ou generalizada ocorre quando toda extensão da armadura é exposta ao agente agressor, ocasionando reações de oxidação e perda uniforme de espessura. $\mathrm{O}$ ataque uniforme é uma forma de corrosão eletroquímica que ocorre com intensidade equivalente ao longo da totalidade de uma superfície exposta, frequentemente deixando para trás uma incrustação ou um depósito (CALLISTER, 2002).

Na corrosão puntiforme ou por pite há um desgaste em pontos ou áreas localizadas, denominadas de pites. Pites são cavidades que apresentam o fundo em forma angulosa e profundidade geralmente maior do que o seu diâmetro (GENTIL, 2014).

Segundo Gentil (2014), a corrosão intergranular é a que se processa entre os grãos da rede cristalina do material metálico. Quando submetida a solicitações mecânicas, pode sofrer fratura frágil, 
perdendo toda condição de utilização. Já a corrosão transgranular é a que se processa em intragrãos da rede cristalina, levando também a fratura quando houver solicitação mecânica.

Já a corrosão ocasionada pelo hidrogênio atômico é chamada de fragilização por hidrogênio, a qual se difunde para o interior do aço ocasionando a fragilização da armadura e consequentemente uma possível fratura na armadura.

Segundo Vieira (2010), a corrosão também pode ser classificada segundo a natureza do processo em química e eletroquímica. A deterioração química, também chamada seca ou oxidação, ocorre na ausência de água e em temperatura acima do ponto de orvalho, ocorre por uma reação gás-metal e forma uma película de óxido. É um processo lento e não provoca deterioração na superfície metálica, exceto se existirem gases agressivos na atmosfera. No concreto armado pode atingir a pasta cimento e os agregados, causando expansão do concreto, lixiviação, vulnerabilidade a ácidos, dentre outras manifestações. A deterioração eletroquímica é o processo de corrosão mais comum na natureza. Ocorre na presença de água líquida devido à formação de pilhas eletroquímicas ou células de corrosão, atacando a armadura do concreto.

O processo de corrosão das armaduras no interior do concreto pode ser classificado como corrosão eletroquímica, que por sua vez ocorre em meio aquoso, havendo a necessidade de um eletrólito, diferença de potencial, oxigênio e agentes agressivos (CANTUÁRIA, 2005).

Andrade (2001), explica que o mecanismo de corrosão eletroquímica é baseado na existência de um desequilíbrio elétrico que pode ocorrer entre metais diferentes ou entre partes distintas de um mesmo metal, configurando o que se chama de pilha de corrosão ou célula de corrosão.

No caso do concreto armado, o processo de corrosão eletroquímica é consequência do fluxo de íons e elétrons entre a região anódica e catódica, através de um eletrólito, que é a própria extensão da armadura. O ferro (Fe), metal presente entre 95 a 97\% do aço, libera íons de ferro para o meio iônico, e elétrons fluem do anôdo para a região catódica através do meio eletrônico, onde reage com o oxigênio e a água, dissolvidos no eletrólito formando íons hidroxila $\left(\mathrm{OH}^{-}\right)$. A água presente na interface entre o concreto e a armadura conduz a hidroxila de volta ao anôdo, a qual reage com os íons de ferro, gerando hidróxido de ferro. A representação esquemática do processo de corrosão eletroquímica é apresentada através da Figura 1.

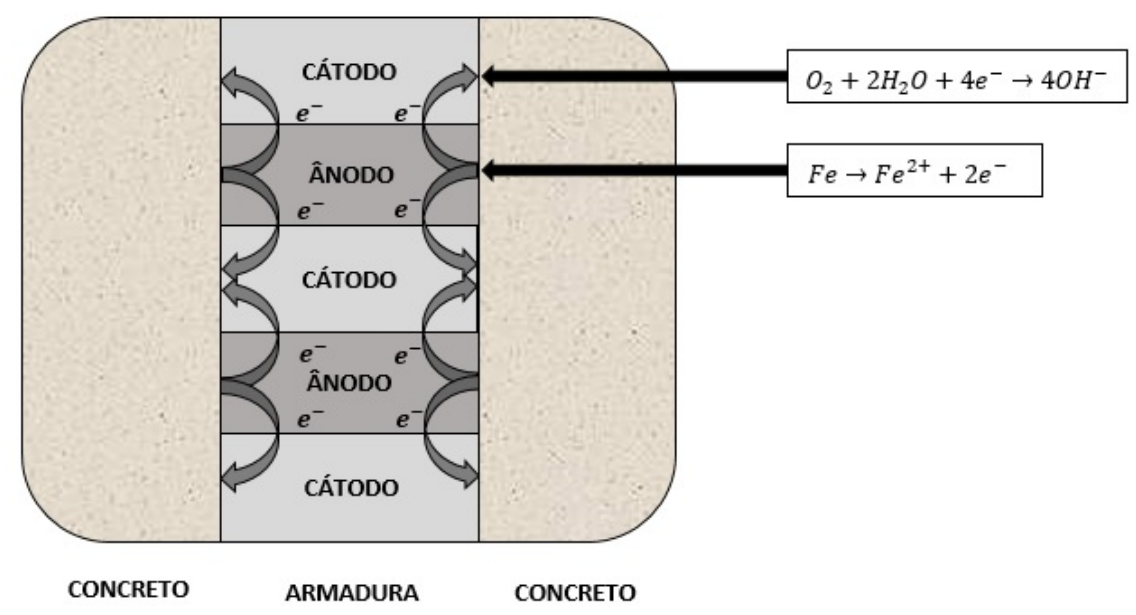

Figura 1 - Representação do processo de corrosão eletroquímica (Adaptado de SOUSA, 2018). A presença das regiões anódica e catódica implica na formação de uma pilha eletroquímica. Portanto, como em uma superfície metálica está presente um grande número de microrregiões anódicas e catódicas, há a formação de uma grande quantidade de pilhas eletroquímicas. A presença de diferentes potenciais eletroquímicos que resultam na formação da pilha é causada pela ocorrência de heterogeneidades físicas e/ou químicas na superfície (CALDAS, 2003). 
O Diagrama de Pourbaix (Figura 2) se baseia em dados da termodinâmica para determinar o comportamento e a estabilidade do metal em três domínios: imunidade, passivação e corrosão. $\mathrm{O}$ estágio inicial é denominado domínio de imunidade, onde o metal se encontra abaixo do seu potencial de equilíbrio, permanecendo estável para todos os valores de $\mathrm{pH}$. Nesse estágio não há ocorrência de corrosão. No domínio de passivação o metal é coberto por uma fina camada de óxidos e hidróxidos, conhecida como camada de passivação, a qual atua como mecanismo de proteção, impedindo que a corrosão avance no metal. No domínio de corrosão ocorre uma instabilidade na camada passivadora que ocasiona a corrosão no metal.

Nas estruturas em concreto armado, a elevada alcalinidade do concreto ( $\mathrm{pH}$ entre 12,5-13,5) favorece a formação de uma película passivadora protetora envolta do aço, resultante de uma reação eletroquímica no domínio de passivação.

Existem algumas teorias para explicar a composição da película passivadora, a mais aceita aponta a formação de uma película composta de duas camadas: uma mais interna, composta principalmente por magnetita e outra mais externa, composta por óxidos férricos (NAGAYAMA; COHEN, 1962 apud FIGUEIREDO; MEIRA, 2013).

De acordo com o Diagrama de Pourbaix (Figura 2), a armadura se mantém estável em domínio de passivação desde que o concreto apresente valores de $\mathrm{pH}$ superiores a 9 em uma faixa usual de potencial de corrosão de $+100 \mathrm{mV}$ a $-400 \mathrm{mV}$ em relação ao eletrodo padrão de hidrogênio. Dessa forma, o concreto proporciona uma alta proteção contra corrosão à armadura, como verificado na Figura 2(a). Quando o metal se encontra em contato com soluções contendo íons cloretos, caso das armaduras de concreto contaminado por cloretos, a armadura estará estável baixando o potencial de corrosão para a zona de passivação perfeita do diagrama de Pourbaix (potencial X pH) para sistema ferro-água com cloretos, como pode ser observado na Figura 2 (b). No caso de estruturas novas, o potencial de proteção deve estar na zona de passivação imperfeita, na qual não é possível o início de corrosão por pites na superfície passiva (RIBEIRO et al., 2018).

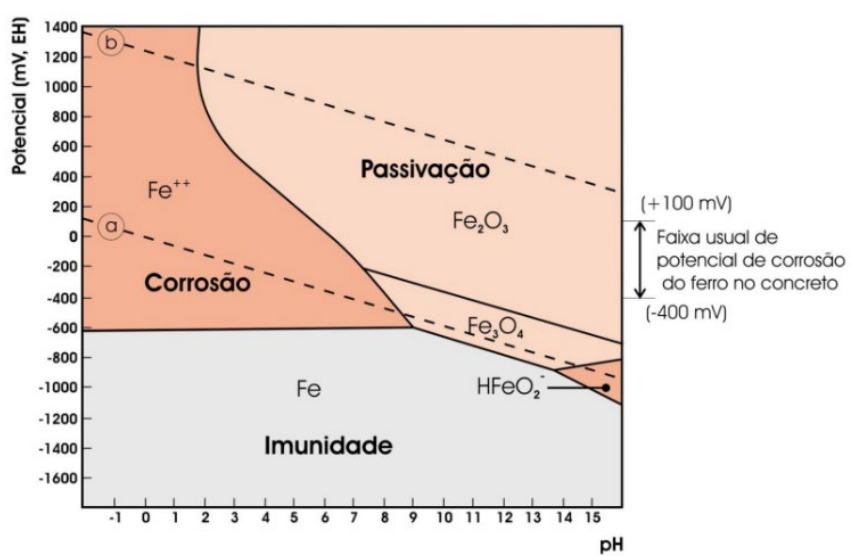

(a) Sistema ferro- $\mathrm{H}_{2} \mathrm{O}$ a $25 \circ \mathrm{C}$.

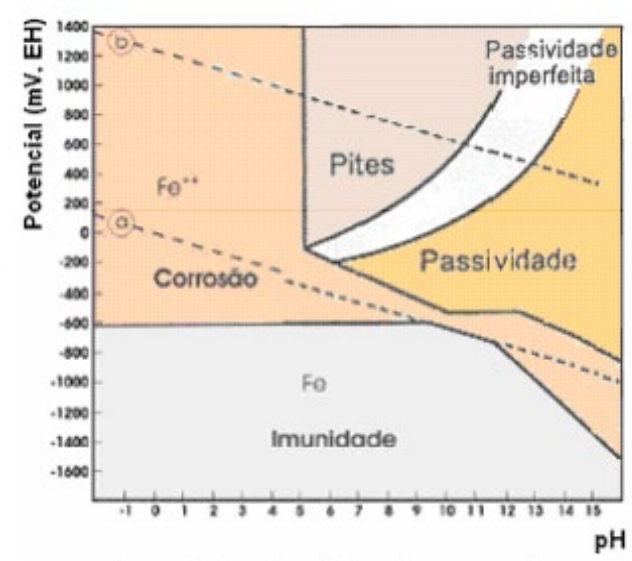

b)Sistema ferro-água com Cl- (355 ppm).

Figura 2. Diagrama de Pourbaix (potencial X pH) (SANTOS, ALBUQUERQUE E RIBEIRO, 2016).

O processo de corrosão ocorre por um desequilíbrio eletroquímico no interior do concreto, devido à penetração de agentes agressores que alteram as condições internas de equilíbrio, destruindo a camada passivadora da armadura. Segundo a ABNT NBR: 6118:2014, os dois principais agentes agressores causadores da despassivação são os íons cloretos e a carbonatação devido, principalmente, ao gás carbônico presente na atmosfera ou em águas agressivas. 


\section{a) Carbonatação}

Na carbonatação, o dióxido de carbono $\left(\mathrm{CO}_{2}\right)$ penetra nos poros do concreto reagindo com a água $\left(\mathrm{H}_{2} \mathrm{O}\right)$ e com o hidróxido de cálcio, $\left(\mathrm{Ca}(\mathrm{OH})_{2}\right)$, proveniente das reações de hidratação da pasta cimento, formando o carbonato de cálcio insolúvel $\left(\mathrm{CaCO}_{3}\right)$. A carbonatação tem sempre o carbonato de cálcio como produto, o qual diminui o $\mathrm{pH}$ do concreto de 12,6 a 13,5 para valores próximos de 8,5 a 9, possibilitando a quebra da camada passivadora do aço, acelerando assim seu processo de deterioração, como mostra a Figura 3.

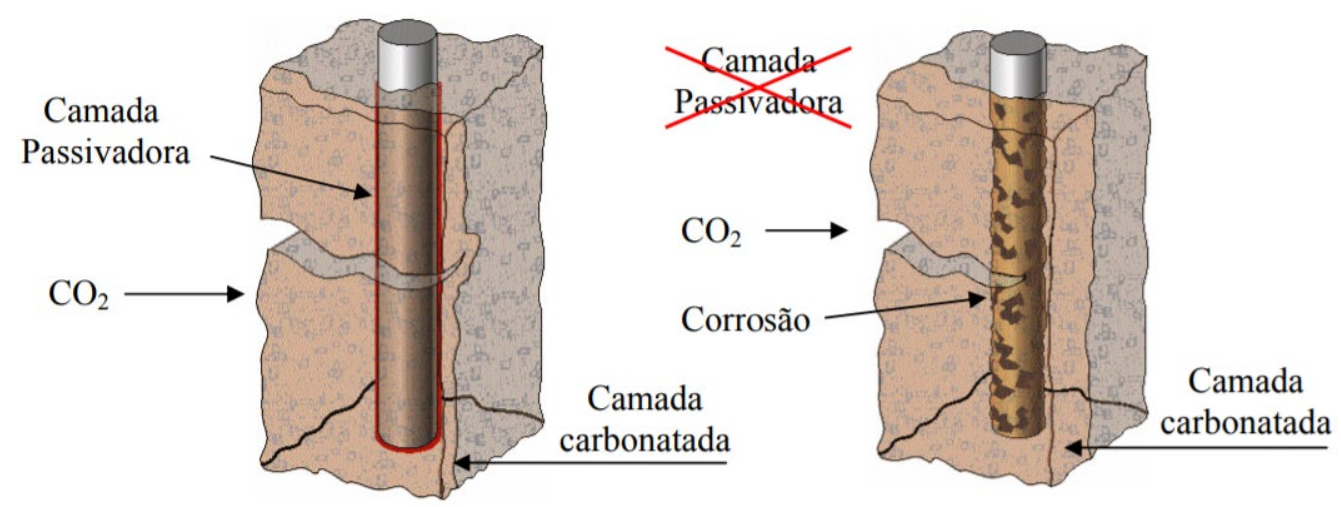

Figura 3 - Representação esquemática da frente de carbonatação (Adaptado de Tutti et al., 2000).

Segundo Montenor, as reações oriundas do processo de carbonatação ocorrem em quatro etapas $1^{\text {a }}$ Etapa: Penetração gasosa do dióxido de carbono $\left(\mathrm{CO}_{2}\right)$ no interior do concreto; $2^{\mathrm{a}}$ Etapa: $\mathrm{O}$ dióxido de carbono $\left(\mathrm{CO}_{2}\right)$ dissolvido nos poros do concreto reage com o hidróxido de cálcio $\left(\mathrm{Ca}(\mathrm{OH})_{2}\right)$; $3^{\mathrm{a}}$ Etapa: Reação com os silicatos e aluminatos; $4^{\mathrm{a}}$ Etapa: O produto final da reação de carbonatação é sempre carbonato de cálcio insolúvel, que, ao se difundir nos poros do concreto, reduz o índice de porosidade, criando assim uma zona de $\mathrm{pH}$ distintos.

b) Ação de Íons Cloreto

Dentre os agentes agressores mais comuns do concreto armado temos os íons cloreto $\left(\mathrm{Cl}^{-}\right)$, os quais atuam tanto no concreto, quanto na armadura, destruindo a camada passivadora do aço, independente do nível de alcalinidade do concreto. As reações abaixo demonstram como o Cl- se comporta no interior do concreto armado, mostrando sua influência, tanto no concreto, quanto na armadura.

$\mathrm{O}$ íon cloreto $\left(\mathrm{Cl}^{-}\right)$reage com a água formando o ácido clorídrico $(\mathrm{HCl})$, o qual baixa o $\mathrm{pH}$ do concreto, quebrando a camada passivadora do aço.

$\mathrm{O}$ íon cloreto $\left(\mathrm{Cl}^{-}\right)$reage com íon ferro (Fe) formando o cloreto férrico $\left(\mathrm{FeCl}_{3}\right)$, o qual reage com a hidroxila $\left(2 \mathrm{OH}^{-}\right)$, resultando em hidróxido de ferro $\mathrm{Fe}(\mathrm{OH})_{2}$ e em uma sobra de íons cloreto disponíveis para reagir novamente, tornando cíclico o processo de reação no interior da estrutura. Diferente da carbonatação, a despassivação da armadura por íons cloreto pode ocorrer independente da alcalinidade do concreto, sendo necessária apenas a presença de $\mathrm{Cl}^{-}$nas proximidades da armadura para acontecer. O processo de corrosão causado por íons cloreto não acontece de forma generalizada, como na carbonatação, mas ocorre de maneira localizada e pontual, e se dando em forma de pites, como mostra a Figura 5. 


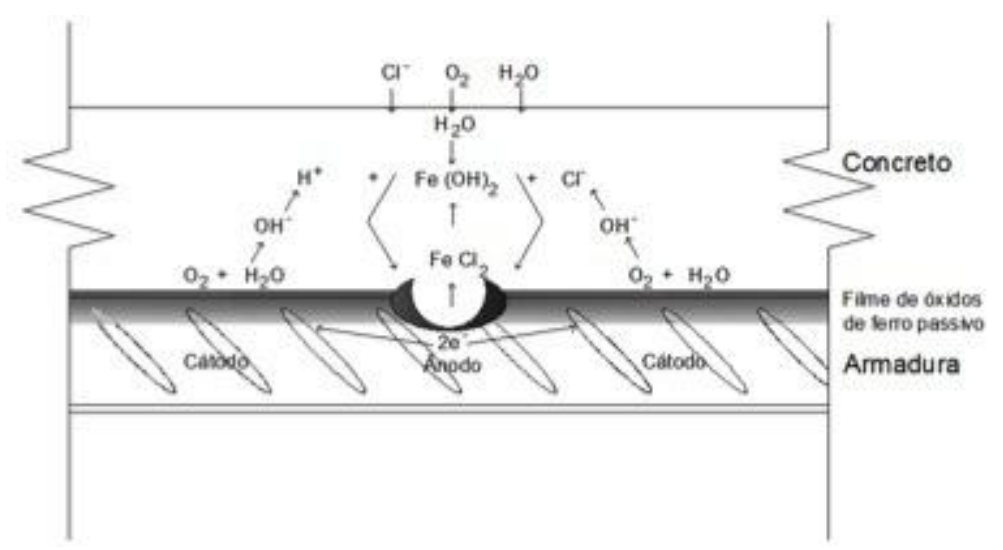

Figura 5. Formação do pite de corrosão pela ação dos cloretos (TREADAWAY, 1988).

$\mathrm{O}$ ataque de íons cloreto tende a ocorrer com maior frequência em regiões litorâneas, devido à exposição das estruturas ou sua proximidade com mar. $\mathrm{O}$ vento exerce papel importante no processo, pois arrastam os íons cloreto presente na atmosfera em direção às estruturas, possibilitando o a penetração de cloretos no concreto.

Dentro do contexto da corrosão das armaduras, há a necessidade de destinar atenção especial à agressividade do macroclima e microclima, haja vista que um dos ambientes de maior agressividade para o concreto armado é a atmosfera salina, principalmente pela ação da maresia, de águas saturadas de sais em contato direto com a estrutura ou névoa salina (FIGUEIREDO, 2005).

\subsection{Fatores aceleradores de corrosão}

\subsubsection{Concentração do dióxido de carbono $\left(\mathrm{CO}_{2}\right)$ no meio ambiente}

A concentração atmosférica de dióxido de carbono em torno do concreto é um parâmetro importante na velocidade do processo de carbonatação, à medida que quanto maior a quantidade de $\mathrm{CO}_{2}$ no ambiente externo, mais rapidamente a estrutura tende a ser carbonatada. A taxa de carbonatação é igualmente superior em ambientes fechados, devido à renovação do ar não ser constante como em ambientes abertos, o que explica o alto índice de incidência de carbonatação em garagens cobertas, proveniente da emissão do $\mathrm{CO}_{2}$ oriundo da exaustão de veículos. $\mathrm{O} \mathrm{CO}_{2}$ está presente em cerca de $0,03 \%$ do volume de ar atmosférico, sendo assim, a NBR 6118/2014 classifica a agressividade do meio em relação a quantidade de dióxido de carbono na atmosfera.

\subsubsection{Umidade relativa do ar}

A carbonatação é um processo físico-químico, isto quer dizer que para que o gás carbônico difuso nos poros do concreto inicie o processo de reação, é necessário que haja a presença de um meio aquoso, um eletrólito que permita que $\mathrm{o}^{\mathrm{CO}_{2}}$ reaja com o hidróxido de cálcio, originando o carbonato de cálcio. Desse modo, o teor de umidade exerce um papel importante na velocidade em que a carbonatação acontece. Nos poros secos, o gás carbônico consegue penetrar mais facilmente, porém não ocorrem reações devido à ausência de um meio aquoso. Em contrapartida, quando os poros do concreto estão saturados, a velocidade de difusão é relativamente mais lenta, pois a velocidade em que o $\mathrm{CO}_{2}$ se difunde na água é quatro vezes menos do que no ar, como mostra a Figura 6. 
(a)

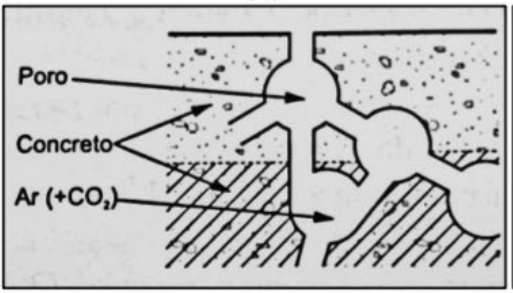

(b)

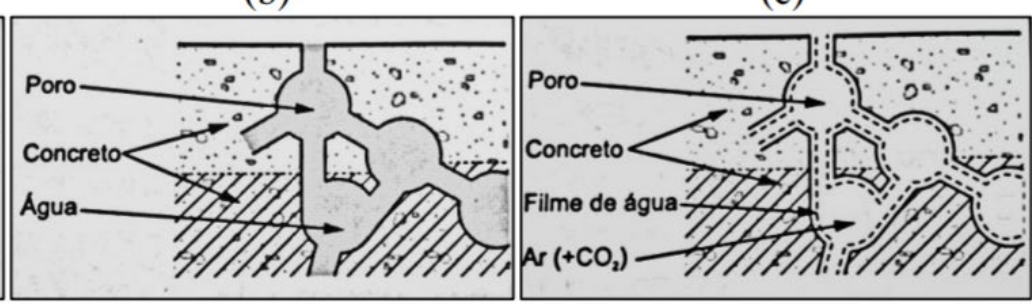

Figura 6. Representação esquemática da carbonatação do concreto: a) poros totalmente secos; b) poros saturados com água; c) poros parcialmente preenchidos com água (concreto com umidade relativa normal ao meio). Adaptado de Cascudo et al. (1997).

Segundo Gouthier (2012), se os poros estiverem totalmente saturados, não ocorrerá carbonatação, mas ocorrerá difusão iônica dos cloretos. Se os poros estiverem parcialmente saturados, ocorrerá tanto carbonatação quanto penetração dos cloretos. Se os poros estiverem completamente secos, não ocorrerá carbonatação, mas poderá ocorrer o ataque por cloretos, caso os mesmos entrem em contato com o concreto através de umidade do ar (caso das estruturas situadas em ambiente de atmosfera marinha), o que permitiria a penetração de íons cloretos por difusão iônica.

A temperatura apresenta uma grande influencia sobre os coeficientes de difusão, sendo que a dependência do coeficiente de difusão com a temperatura pode ser expressa pela lei de Arrhenius, na qual o incremento de temperatura provoca o incremento da velocidade das reações químicas segundo uma lei exponencial (CALLISTER, 2002).

\subsubsection{Características do concreto}

A qualidade do concreto exerce grande influencia sobre a porosidade da estrutura. Concretos mais porosos facilitam a difusão de agentes contaminantes para o interior da estrutura. A relação água/cimento define as características dos poros do concreto, influenciando diretamente sua qualidade. Quanto menor a relação a/c, maior será a resistência do concreto e a proteção contra agentes agressores, em contra partida, quanto maior a relação, maior será a porosidade da pasta de cimento endurecido, o que torna o concreto mais vulnerável a difusão de $\mathrm{CO}_{2}$ e íons cloreto, e, portanto, mais suscetível a degradar.

Outro fator de influencia direta na qualidade é o tempo de cura. Bazan (2014) explica que quanto maior o tempo e a qualidade do processo de cura, maior será o ganho das propriedades do concreto, apresentando uma menor porosidade e consequentemente uma menor permeabilidade a agentes agressores.

O concreto atua não apenas como uma proteção eletroquímica para as armaduras, mas também como uma barreira física, sendo assim, a altura de cobrimento adequada retarda o tempo em que agentes agressores dissolvidos no concreto possam chegar até as armaduras. A NBR 6118:2014 relaciona os cobrimentos mínimos necessários, em função da classe de agressividade em que a estrutura está exposta.

\subsection{Métodos de Proteção}

\subsubsection{Revestimentos}

A definição do tipo de revestimento a ser utilizado para proteção de fachadas de edificações, não deve ser realizada levando em consideração apenas o aspecto estético, tendo em vista que os materiais que 
irão compor o revestimento devem apresentar uma boa resistência às ações externas. Os principais tipos de revestimentos utilizados para esta finalidade são os revestimentos argamassados, cerâmicos e pétreos (NASCIMENTO, 2016). Se tratando de estruturas de concreto armado, sua função é envolver a superfície do concreto, impedindo a entrada de agentes agressores. Nesse caso, além da camada de cobrimento de concreto, que atua como uma barreira de proteção física para as armaduras, é criada uma camada extra de proteção. Além dos métodos de revestimentos convencionais, estudos apontam que revestimentos de geopolímeros à base de metaculim e revestimentos argamassados modificados com polímeros, apresentam efeitos ainda mais retardadores da penetração de cloretos no concreto (AGUIRRE-GUERRERO; ROBAYO-SALAZA; GUTIÉRREZ, 2017; BRENNA et al., 2013).

Além disso, revestimentos acrílicos também oferecem um nível de proteção satisfatório contra a carbonatação, enquanto os revestimentos elastoméricos podem proteger os vergalhões da corrosão de íons cloreto (ZAFEIROPOULOU; RAKANTA; BATIS, 2011).

\subsubsection{Inibidores de corrosão}

Inibidor de corrosão é um composto químico que quando introduzido no concreto em quantidades reduzidas, pode evitar ou diminuir corrosão das armaduras sem afetar negativamente as propriedades físicas ou microestrutura do concreto (POLITO, 2006).

Em estruturas que sofrem com a corrosão, os inibidores podem ser utilizados como aditivos no concreto de reparação, ou em pontos específicos, a depender do percentual de degradação. O tipo mais comum utilizado nas estruturas é o nitrato de cálcio $\left(\mathrm{Ca}\left(\mathrm{NO}_{3}\right)_{2}\right)$, um inibidor anódico que ao reagir com o íon ferroso cria uma película aderente de óxido de ferro ao redor da armadura.

Os inibidores podem ser utilizados em diferentes aplicações, o mais recomendado é a adição junto à pasta de cimento como método preventivo em novas estruturas. Pode-se aplica-los também juntamente com argamassa de proteção durante o processo de reabilitação em estruturas já degradadas, bem como pintura de revestimento no exterior das estruturas.

Apesar da ampla utilização no processo de recuperação, a aplicação recomendável dos inibidores é durante o período de concepção das estruturas. A adição de inibidores na pasta cimento retarda o processo de corrosão, prolongando a vida útil da estrutura. Segundo Grosser (2015), os inibidores são de fácil aplicação e oferecem a vantagem de utilização in-situ sem causar problemas durante o processo.

De acordo com a origem, podem ser sintéticos, que são produzidos artificialmente e naturais, que não são agressivos ao meio ambiente. Segundo sua constituição química, os inibidores podem ser classificados de acordo com sua natureza em orgânicos ou inorgânicos.

Os inibidores orgânicos incluem principalmente aminas e ésteres. Eles oferecem proteção pela adsorção e formação de um filme monomolecular na superfície da armadura e às vezes retardam a chegada de íons cloretos na armadura. Normalmente, há um grupo de moléculas orgânicas que se adsorvem ao metal e uma cadeia não polar hidrofóbica orientada perpendicular a esta superfície (FREIRE, 2005).

Algumas investigações têm sido feitas recentemente sobre o uso de substâncias naturais para a inibição de corrosão dos metais em ambientes ácidos. Pesquisas de substâncias naturais inibidoras da corrosão têm atraído uma atenção considerável porque elas possuem um baixo custo, são propícias ecologicamente e não constituem uma ameaça ao ambiente (BOLINA, 2008).

\subsubsection{Proteção Catódica}

A proteção catódica é um método eletroquímico utilizado no processo de oxirredução para controle da corrosão. Consiste na aplicação de uma fonte externa de energia ligada ao ânodo, que seja mais eletronegativa que o aço em estado de corrosão, a fim de produzir uma corrente catódica contínua 
entre a armadura e o eletrodo externo, revertendo o potencial de corrosão e assumindo o papel do ânodo, tonando então a armadura catódica. A zona posterior de abrangência se torna zona neura, ou seja, não suscetível à corrosão.

A aplicação da corrente de proteção reduz a velocidade de corrosão do metal, baixando o potencial, para valores inferiores ao potencial de equilíbrio do metal no meio ambiente exposto, isto é, para a zona de imunidade do diagrama potencial-pH, ou para a zona de passivação, dependendo do metal e do ambiente a que está exposto. $\mathrm{Na}$ prática, não é necessário eliminar completamente a corrosão (proteção total ou imunidade), mas sim reduzir a velocidade de corrosão para valores insignificantes (LOURENÇO, 2014).

Existem dois métodos principais para aplicação da proteção catódica: método por do ânodo galvânico ou ânodo por sacrifício e método tradicional por corrente impressa. Na proteção por ânodos de sacrifício o metal a proteger é conectado diretamente a um metal ativo com potencial de corrosão inferior, que se dissipa gradualmente, gerando assim uma corrente iônica entre o ânodo e a armadura. Os metais mais utilizados como ânodos de sacrifício são: zinco, ligas de magnésio e algumas ligas de alumínio. No método por corrente impressa utiliza-se um gerador exterior de corrente contínua ligada ao anodo. $\mathrm{O}$ cátodo é a superfície da armadura e o concreto o eletrólito. $\mathrm{O}$ método por corrente impressa é o mais utilizado em estruturas de concreto armado em contato com a atmosfera.

Segundo SOUZA (2014), a corrente elétrica gerada no processo também provoca modificações químicas no concreto. A principal reação que ocorre na interface entre o concreto e o aço é a redução de oxigênio e a produção de íons hidróxido, como mostra a Figura 7.

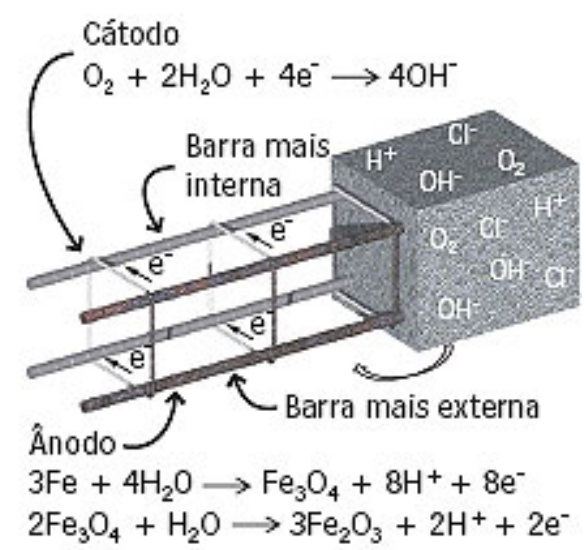

Figura 7. Representação esquemática da produção de íons hidróxido. Fonte: Adaptado de Vieira et al. (2010).

Apesar de contribuir para o aumento do $\mathrm{pH}$ do concreto e da restauração da camada passivadora, a produção de hidrogênio pode causar fragilidade na armadura por consequência da penetração do hidrogênio atômico.

A reparação da estrutura degradada requer a eliminação superficial do concreto danificado ao redor da zona de exposição. Neste caso deve-se analisar a deterioração no interior, caso haja uma perda de $10 \%$ da seção nominal de projeto, é necessário que haja um reforço estrutural. Caso contrário, deve ser feita a retirada do concreto para que se realize uma limpeza nas armaduras e a instalação do ânodo por sacrifício ou do gerador de corrente iônica, tornando toda a superfície das armaduras em cátodo. A zona posterior de abrangência se torna então uma zona neutra, ou seja, não gera corrosão. Após a estabilidade do processo, o concreto é recomposto através da aplicação de uma argamassa de reparação. 


\subsection{Métodos de Recuperação}

\subsubsection{Realcalinização}

A realcalinização é um procedimento empregado para reestabelecimento do $\mathrm{pH}$ do concreto carbonatado utilizando soluções de álcalis, com ou sem o uso de corrente elétrica, para níveis alcalinos que possibilitem a reconstituição da película passivadora do aço. É considerada tanto uma medida preventiva, quanto corretiva, e apresenta a vantagem de não exigir a retirada prévia do concreto carbonatado.

Segundo Araújo (2009), existem três métodos para a realcalinização do concreto. O primeiro é através da difusão e absorção de uma solução alcalina para o interior do concreto, através de ação capilar e forças hidráulicas, sem que haja a qualquer dependência de campo elétrico e de fluxo de corrente (realcalinização química), como mostra a Figura 8. O segundo e o terceiro são considerados realcalinização eletroquímica. O segundo ocorre através da produção de íons hidroxila, devido à reação catódica na superfície das armaduras, como mostra a Figura 9. E o terceiro ocorre através de um fluxo-osmótico, que transporta a solução alcalina para o interior dos poros.

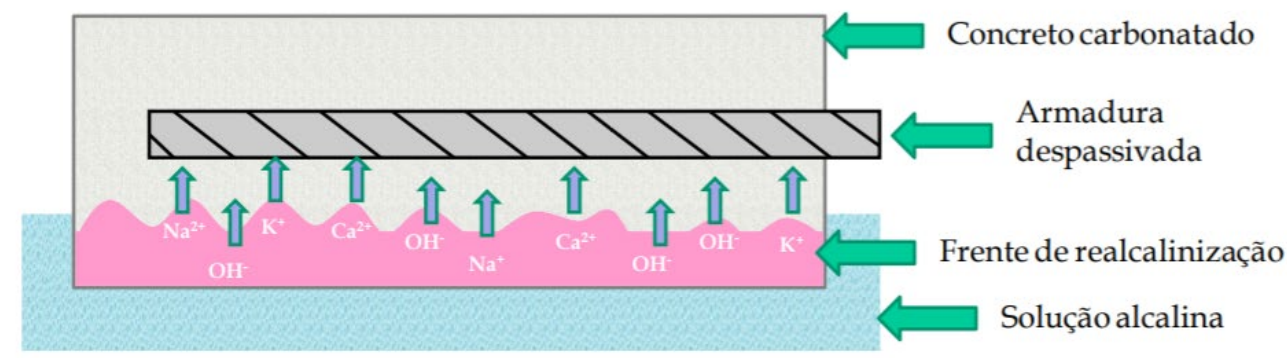

Figura 8. Esquema da realcalinização química. Adaptado de Araújo et al. (2004).

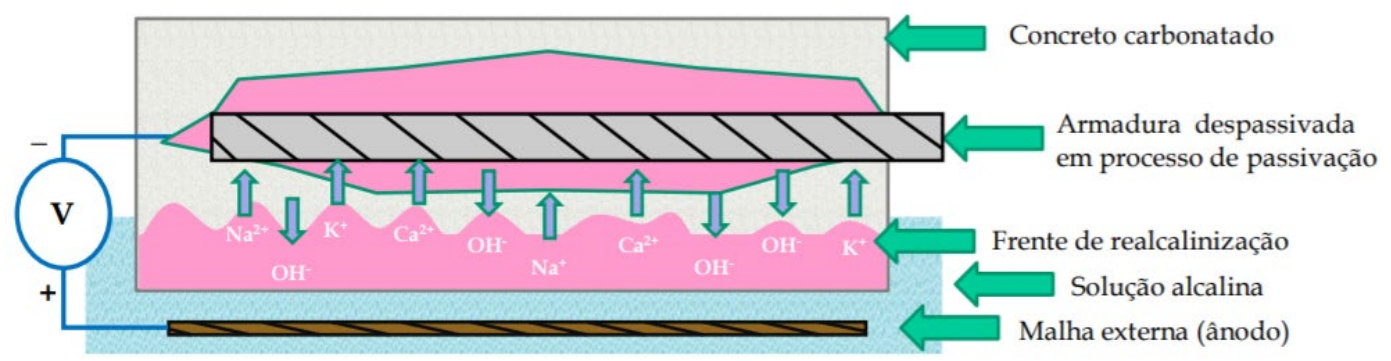

Figura 9. Princípio da realcalinização eletroquímica. Adaptado de Araújo et al. (2004).

\subsubsection{Dessalinização}

A dessalinização, também chamada de extração eletroquímica de cloretos, é o processo de restauração da estrutura degradada que consiste em remover os íons cloreto mediante a aplicação de uma corrente elétrica contínua, sem que haja a necessidade da retirada do concreto contaminado. Monteiro (2002) explica que a dessalinização consiste na aplicação de um campo elétrico entre a armadura no interior do concreto e um eletrodo constituído por uma malha metálica fixada externamente à superfície do concreto e colocada no interior de um reservatório de eletrólito. Com a aplicação da corrente, íons negativos são atraídos para o ânodo colocado externamente a 
superfície do concreto. Ocorre também a migração de cátions $\left(\mathrm{NA}^{+}\right)$para as armaduras e produção de íons hidroxila $\left(\mathrm{OH}^{-}\right)$na superfície das armaduras, como consequência das reações catódicas. Esse processo está descrito abaixo, pela Figura 10, bem como seus elementos e a movimentação dos íons cloretos.

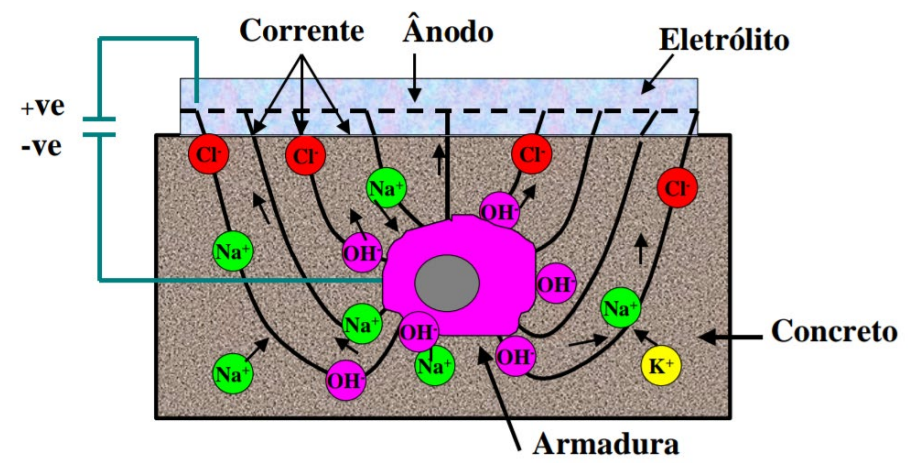

Figura 10. Princípios da extração eletroquímica de cloretos. Fonte: Adaptado de NCT et al. (1996).

\section{CONCLUSÕES}

A corrosão nas armaduras do concreto armado pode ser evitada utilizando métodos de proteção aplicados diretamente na armadura ou na mistura do concreto. Além disso, proteger a superfície do concreto a partir de métodos de revestimento adequados também é imprescindível. Esses produtos de proteção de superfície tendem a elevar a vida útil do concreto armado e das edificações em geral.

Nos ataques causados por carbonatação, utilizam-se mais frequentemente como métodos de proteção, as técnicas de aplicação de revestimentos e inibidores de corrosão. Podendo-se utilizar a realcalinização para recuperação de estruturas carbonatadas. Já para a degradação causada por íons cloreto, o método de proteção mais utilizado e também mais frequente na literatura é a proteção catódica.

\section{AGRADECIMIENTOS}

Área 1 - Faculdade de Ciência e Tecnologia, ÁREA1/CBES, Brasil

\section{REFERENCIAS}

AGUIRRE-GUERRERO, A. M.; ROBAYO-SALAZAR, R.A.; GUTIÉRREZ, R. M. A novel geopolymer application: Coatings to protect reinforced concrete against corrosión. Applied Clay Science, Volume 135, Pages 437-446, 2017.

ASSOCIAÇÃO BRASILEIRA DE NORMAS TÉCNICAS. NBR 6118: Projeto de estruturas de concreto - Procedimento. 238p. Rio de Janeiro, 2014.

ANDRADE, J.J.O. Contribuição à previsão da vida útil das estruturas de concreto armado atacadas pela corrosão de armaduras: Iniciação por cloretos. Tese de doutorado. Escola de Engenharia, Universidade Federal do Rio Grande do Sul. Porto Alegre,2001, 249 p 
BAZAN, G.C.G. Análise do cobrimento e carbonatação em obras de arte especiais no estado de São Paulo. Trabalho de Conclusão de curso. Escola Politécnica da Universidade de São Paulo. São Paulo: 2014, 151 p.

BOLINA, C.D.C. Inibidores de corrosão: Avaliação do desempenho frente a corrosão do aço induzida por carbonatação e cloretos. Dissertação de Mestrado em Engenharia Civil da Universidade Federal de Goiás. Goiânia: 2008.

BRENNA, A.; BOLZONI, F.; BERETTA, S.; ORMELLESE, M. Long-term chloride-induced corrosion monitoring of reinforced concrete coated with commercial polymer-modified mortar and polymeric coatings. Construction and Building Materials, Volume 48, Pages 734-744, 2013.

CANTUÁRIA, L.L.; CARDOSO, E.N. Análise do processo de passivação das armaduras no concreto. Trabalho de conclusão de curso. Coordenação de Construção Civil, Centro Federal de Educação Tecnológica de Goiás. Goiânia: 2005, 81 p.

CASCUDO, Oswaldo. O controle da corrosão de armaduras em concreto: inspeção e técnicas eletroquímicas. $1^{a}$ ed. Goiânia: Editora UFG, 1997. 237p.

CEB. Durability of concret structures. Report of CEB-RILEM Internacional Workshop. Copenhague: 1983; CEB Bulletin D’Information. N9 152, 1984.

FIGUEIREDO, Enio Pazini. Efeitos da carbonatação e de cloretos no concreto. In: ISAIA, Geraldo Cechella (Ed.). Concreto: ensino, pesquisa e realizações. São Paulo: IBRACON, 2005. 2v. Cap.27, p.829-855.

GENTIL, V. Corrosão. 6 ${ }^{\mathrm{a}}$ ed, Rio de Janeiro: LTC, 2014. 210-221 p.

GOUTHIER, M, R. Deterioração das estruturas de concreto armado - estudo de caso. Dissertação de especialização em engenharia civil. Escola de Engenharia da UFMG, Belo Horizonte, 2012.

GROSSER, F. N. Inibidores orgânicos de corrosão - Estudos com compostos naturais, obtidos de diversas espécies de mentas. Tese de Doutorado, Universidade Federal do Rio Grande do Sul, Porto Alegre, julho de 2015.

LOURENÇO, M. Zita. Corrosão em estruturas de concreto armado: técnicas Eletroquímicas para a reabilitação de estruturas. $1^{\circ}$ edição, Rio de Janeiro, Elsevier, 2014.

NASCIMENTO, MATHEUS LEONI MARTINS. Aplicação da Simulação Higrotérmica na Investigação da Degradação de Fachadas de Edifícios. [Distrito Federal] 173p., ENC/FT/UnB, Mestrado em Estruturas e Construção Civil, 2016.

Dissertação de Mestrado - Universidade de Brasília. Faculdade de Tecnologia.

OLIVEIRA, G. A. Avaliação da durabilidade de concretos contendo agregados reciclados de resíduos de construção civil (RCC). Dissertação (Mestrado em Engenharia Civil), Universidade Federal da Bahia, Salvador, 2017.

POLITO, G. Corrosão em estruturas de concreto armado: Causas, mecanismos, prevenção e recuperação. Trabalho de conclusão de curso. Universidade Federal de Minas Gerais, Belo Horizonte: 2006, 191 p.

RIBEIRO, D. V. Corrosão. In: RIBEIRO, D. V; SALES, A.; SOUSA, C. A. A.; ALMEIDA, F. C. R.; CUNHA, M. P. T.; LOURENÇO, M. Z.; HELENE, P. Corrosão em Estruturas de Concreto Armado: Teoria, Controle e Métodos de Análise. 2a edição. Rio de Janeiro: Elsevier, 2018.

SOUZA, C, A, C. Corrosão em estruturas de concreto armado: Métodos de proteção e aumento da durabilidade do concreto armado. In: RIBEIRO, D. V. $1^{\circ}$ edição, Rio de Janeiro, Elsevier, 2014. VIEIRA, F.M.P. Contribuição ao estudo da corrosão de armaduras em concretos com adição de sílica ativa. Tese de Doutorado. Escola de Engenharia, Universidade Federal do Rio Grande do Sul. Porto Alegre: 2010, 242 p.

ZAFEIROPOULOU, T.; RAKANTA, E.; BATIS, G. Performance evaluation of organic coatings against corrosion in reinforced cement mortars. Progress in Organic Coatings, Volume 72, Issues 1-2, Pages 175-180, September-October 2011. 